\title{
Target-Dependent Control of Synaptic Inhibition by Endocannabinoids in the Thalamus
}

\author{
Yan-Gang Sun, ${ }^{1}$ Chia-Shan $\mathrm{Wu},{ }^{2}$ Hui-Chen $\mathrm{Lu},{ }^{2}$ and Michael Beierlein ${ }^{1}$ \\ ${ }^{1}$ Department of Neurobiology \& Anatomy, University of Texas Medical School, Houston, Texas 77030, and ${ }^{2}$ The Cain Foundation Laboratories, Jan and Dan \\ Duncan Neurological Research Institute, Department of Pediatrics, Baylor College of Medicine, Houston, Texas 77030
}

Inhibitory neurons in the thalamic reticular nucleus (TRN) play a critical role in controlling information transfer between thalamus and neocortex. GABAergic synapses formed by TRN neurons contact both thalamic relay cells and neurons within TRN. These two types of synapses are thought to have distinct roles for the generation of thalamic network activity, but their selective regulation is poorly understood. In many areas throughout the brain, retrograde signaling mediated by endocannabinoids acts to dynamically regulate synaptic strength over both short and long time scales. However, retrograde signaling has never been demonstrated in the thalamus. Here, we show that depolarization-induced suppression of inhibition (DSI) is prominent at inhibitory synapses interconnecting TRN neurons. DSI is completely abolished in the presence of a cannabinoid receptor 1 (CB1R) antagonist and in mice lacking CB1Rs. DSI is prevented by DAG lipase inhibitors and prolonged by blocking the 2-arachidonoylglycerol (2-AG) degradation enzyme monoacylglycerol lipase, indicating that it is mediated by the release of 2-AG from TRN neurons. By contrast, DSI is not observed at TRN synapses targeting thalamic relay neurons. A combination of pharmacological and immunohistochemical data indicate that the differences in endocannabinoid signaling at the two synapses are mediated by a synapse-specific targeting of CB1Rs, as well as differences in endocannabinoid release between the two target neurons. Together, our results show that endocannabinoids control transmitter release at specific thalamic synapses, and could dynamically regulate sensory information processing and thalamus-mediated synchronous oscillations.

\section{Introduction}

The thalamus is the central gateway for the processing of sensory information (Jones, 2007) and, in addition, has a critical role in the generation of rhythmic oscillations in the thalamocortical system (Buzsáki, 2006). Reciprocal connections between thalamic relay cells and neurons in the thalamic reticular nucleus (TRN) underlie oscillatory activity such as sleep spindles (McCormick and Bal, 1997; Huguenard and McCormick, 2007). Burst firing in TRN neurons evokes a strong hyperpolarization of thalamocortical relay cells, mediated by the activation of postsynaptic $\mathrm{GABA}_{\mathrm{A}}$ and $\mathrm{GABA}_{\mathrm{B}}$ receptors (von Krosigk et al., 1993; Huguenard and Prince, 1994). In turn, this leads to the deinactivation of low-threshold, T-type $\mathrm{Ca}^{2+}$ channels (Llinás and Jahnsen, 1982; Huguenard, 1996), which enables relay neurons to produce a postinhibitory rebound calcium spike that can trigger bursts of fast action potentials. Finally, this burst-evoked excitation is transmitted back to cells in the reticular nucleus, via axon collaterals of thalamocortical projections. Since the inhibition of

\footnotetext{
Received Jan. 26, 2011; revised April 5, 2011; accepted May 3, 2011.

Author contributions: Y.-G.S., C.-S.W., H.-C.L., and M.B. designed research; Y.-G.S., C.-S.W., H.-C.L., and M.B. performed research; Y.-G.S., C.-S.W., H.-C.L., and M.B. analyzed data; Y.-G.S., C.-S.W., H.-C.L., and M.B. wrote the paper.

This work was supported in part by funds from DA029381 (NIDA) and HD065561 (NICHD) to H-C.L., and the American Heart Association and the Whitehall Foundation to M.B. We thank Jie Zhu for technical support, Dr. Beat Lutz for sharing CB1R knock-out mice, Dr. Ken Mackie for CB1R antibodies, and the Baylor Intellectual and Developmental Disabilities Research Center core facility (NIH HD024064) for confocal microscopy access.

Correspondence should be addressed to Michael Beierlein, Department of Neurobiology \& Anatomy, University of Texas Medical School, 6431 Fannin, Suite 7.046, Houston, TX 77030. E-mail: michael.beierlein@uth.tmc.edu.

DOI:10.1523/JNEUROSCI.0531-11.2011

Copyright $\odot 2011$ the authors $\quad 0270-6474 / 11 / 319222-09 \$ 15.00 / 0$
}

relay neurons is mediated exclusively by TRN neurons, it is important to understand how their activity is regulated. TRN neurons are interconnected by both chemical (Bal et al., 1995; Sanchez-Vives and McCormick, 1997; Zhang and Jones, 2004; Deleuze and Huguenard, 2006; Lam et al., 2006) and electrical (Landisman et al., 2002; Deleuze and Huguenard, 2006) synapses. GABAergic synapses formed between TRN neurons are thought to be important for limiting the fraction of TRN neurons that participate in rhythmic oscillatory activity (Sanchez-Vives and McCormick, 1997; Sohal and Huguenard, 2003). In contrast, electrical synapses are assumed to mediate synchronous firing within local clusters of TRN neurons (Long et al., 2004; Cruikshank et al., 2005).

A number of studies have shown that intra-TRN inhibition mediated by chemical synapses is essential in keeping thalamic circuits from entering a hypersynchronous state. When intraTRN inhibition is blocked pharmacologically or genetically (Huntsman et al., 1999), a higher percentage of TRN neurons participates in oscillatory activity, which can result in the development of seizure-like activity (McCormick and Bal, 1997; Huguenard and McCormick, 2007; Beenhakker and Huguenard, 2009). Little is known about the mechanisms that regulate intraTRN synaptic activity and, specifically, whether inhibitory synaptic strength is reduced during increased levels of neuronal activity, leading to a higher degree of thalamic synchrony. Activity-dependent changes in synaptic strength could be mediated by retrograde messengers such as endocannabinoids (Regehr et al., 2009), but a role for retrograde signaling in the thalamus has never been demonstrated. 
Here we have investigated this issue, by examining the role of retrograde signaling at inhibitory synapses formed by TRN neurons onto two distinct targets, neighboring TRN neurons and cells in the ventrobasal nucleus of the thalamus (VB). We found that depolarization of TRN neurons led to prominent suppression of inhibitory synaptic strength (DSI), mediated by the calcium-dependent release of 2-arachidonoylglycerol (2-AG) from TRN neurons acting on presynaptic type 1 cannabinoid receptors (CB1Rs). By contrast, DSI was absent at TRN synapses contacting thalamic relay neurons. Thus, target-dependent endocannabinoid signaling in thalamic circuits could be critical in dynamically regulating the degree of synchronous activity.

\section{Materials and Methods}

Slice preparation. Thalamocortical slices $(400 \mu \mathrm{m})$ were prepared as described previously (Agmon and Connors, 1991). Briefly, C57BL/6 wild-type mice (P13-P17) of either sex or CB1R knock-out animals (Marsicano et al., 2002) and their wild-type littermates were anesthetized with isoflurane and decapitated, according to procedures approved by the University of Texas Health Science Center at Houston animal welfare committee. Slices were cut in ice-cold, oxygenated solution containing (in mM) 111 choline $\mathrm{Cl}, 2.5 \mathrm{KCl}, 1.25 \mathrm{NaH}_{2} \mathrm{PO}_{4}, 10 \mathrm{MgSO}_{4}, 26 \mathrm{NaHCO}_{3}$, 10 glucose, and $0.5 \mathrm{CaCl}_{2}$, saturated with $95 \% \mathrm{O}_{2}-5 \% \mathrm{CO}_{2}$, using a vibratome (Leica VT1200S) at slicing speeds of $0.2 \mathrm{~mm} / \mathrm{s}$ and a blade vibration amplitude of $0.8 \mathrm{~mm}$. Slices were incubated at $34^{\circ} \mathrm{C}$ for $40 \mathrm{~min}$, in saline solution containing (in mM) $126 \mathrm{NaCl}, 26 \mathrm{NaHCO}_{3}, 2.5 \mathrm{KCl}$, $1.25 \mathrm{NaH}_{2} \mathrm{PO}_{4}, 10$ glucose, $2 \mathrm{CaCl}_{2}$, and $2 \mathrm{MgCl}_{2}$, and then held at room temperature before recordings.

Electrophysiology. Slices were placed on glass coverslips coated with polyL-lysine (Sigma), and submerged in a recording chamber (Warner Instruments). All recordings were performed at near-physiological temperatures $\left(32-34^{\circ} \mathrm{C}\right)$ using an in-line heater (Warner Instruments) while perfusing the recording chamber with solution at $3-4 \mathrm{ml} / \mathrm{min}$ using a Minipulse 3 pump (Gilson). Whole-cell recordings were obtained under IR-DIC visualization using an Olympus BX51WI microscope (Olympus Optical) and a CCD camera (Hamamatsu). Recording pipettes (2-3 M $\Omega$ ) contained the following (in mM): $93 \mathrm{CsMeSO}_{3}, 40 \mathrm{CsCl}, 10 \mathrm{HEPES}, 0.5$ EGTA, 2 $\mathrm{MgCl}_{2}, 0.16 \mathrm{CaCl}_{2}, 2 \mathrm{Mg}$-ATP, $0.4 \mathrm{Na}-\mathrm{GTP}$, and 2 2(triethylamino)- $\mathrm{N}$ (2,6-dimethylphenyl)acetamide (QX-314), adjusted to $295 \mathrm{mOsm}$ and $\mathrm{pH}$ 7.3. For experiments examining depolarization-induced suppression of excitation (DSE) in VB neurons, cells were recorded with an internal solution containing the following (in mM): $120 \mathrm{CsMeSO}_{3}, 11 \mathrm{CsCl}, 10 \mathrm{HEPES}, 11$ EGTA, $1 \mathrm{MgCl}_{2}, 1 \mathrm{CaCl}_{2}, 2 \mathrm{Mg}$-ATP, $0.3 \mathrm{Na}-\mathrm{GTP}$, and $2 \mathrm{QX}-314$, adjusted to $295 \mathrm{mOsm}$ and $\mathrm{pH}$ 7.3. For experiments examining electrical coupling, pairs of neighboring TRN cells were recorded with a potassium-based internal solution containing the following (in $\mathrm{mM}$ ): $130 \mathrm{~K}$-gluconate, $10 \mathrm{NaCl}, 10$ HEPES, 0.5 EGTA, $0.16 \mathrm{CaCl}_{2}, 4 \mathrm{Mg}$-ATP, and 0.4 Na-GTP. Cells were clamped using a Multiclamp 700B amplifier (Molecular Devices), at access resistances of $8-15 \mathrm{M} \Omega$. Access resistance and leak current were continually monitored, and experiments were discarded if either increased by $>20 \%$. Synaptic inputs were activated with brief pulses (200 $\mu$ s, 10-30 $\mu \mathrm{A})$, using glass electrodes filled with ACSF. All experiments except those in Figure 3 were performed in the presence of 2,3-dihydroxy-6-nitro-7-sulfamoylbenzo[f]quinoxaline (NBQX, $10 \mu \mathrm{M}), 3-[(R)$-2-carboxypiperazin-4-yl]propyl-1-phosphonic acid (R-CPP, $5 \mu \mathrm{M})$, and (2S)-3-\{[(1S)-1-(3, 4-dichlorophenyl)ethyl]amino-2-hydroxypropyl\} (phenylmethyl) phosphinic acid (CGP 55845, $5 \mu \mathrm{M}$ ) to block AMPA, NMDA, and GABA $\mathrm{B}_{\mathrm{B}}$ receptors, respectively. In experiments testing the role of diacylglycerol lipase (DAGL), slices were incubated in $100 \mu \mathrm{M}$ 1,6-bis(cyclohexyloximinocarbonylamino)hexane (RHC80267) for $1 \mathrm{~h}$. Recordings were performed in the continuous presence of $30 \mu \mathrm{M}$ RHC80267. For experiments using U73122 and JZL184, slices were incubated in $5 \mu \mathrm{M}$ U73122 and $200 \mathrm{nM}$ JZL184 for $1 \mathrm{~h}$, respectively. Recordings were performed in the continuous presence of U73122 (5 $\mu \mathrm{M})$ and JZL184 (200 nM), respectively.

$N$-(Piperidin-1-yl)-5-(4-iodophenyl)-1-(2,4-dichlorophenyl)-4-methyl$1 \mathrm{H}$-pyrazole-3-carboxamide (AM251), WIN 55,212-2, R-CPP, NBQX, U73122, picrotoxin, and CGP 55845 were purchased from Tocris Cookson;
$\mathrm{Cs}_{4} \mathrm{BAPTA}$ was obtained from Invitrogen. All other chemicals were obtained from Sigma.

Data acquisition and analysis. Recordings were filtered at $2-4 \mathrm{kHz}$ and digitized at $20 \mathrm{kHz}$ with a 16 bit analog-to digital converter (Digidata 1440A, Molecular Devices). Data were acquired using pClamp software (Molecular Devices). Data analysis was performed with custom macros written in Igor Pro (Wavemetrics). Statistical test were performed with the unpaired or paired Student's $t$ test. Differences are considered to be significant at $p<0.05$. Data are expressed as mean \pm SEM.

Immunohistochemistry. Immunohistochemical staining was performed as described previously (Wu et al., 2010). To generate a double transgenic Dlx (distal-less homeobox) 5/6-Cre-Tau ${ }^{\text {mGFP }}$ mouse line (referred to as dlx-mGFP), we crossed Dlx5/6-Cre mice (Potter et al., 2009) with Tau ${ }^{\text {mGFP }}$ mice (Hippenmeyer et al., 2005). The Dlx5/6-Cre transgenic mouse line (The Jackson Laboratory) expresses Cre in inhibitory neurons. Tau ${ }^{\text {mGFP }}$ mice belong to a Cre-reporter line that has a loxp flanked transcriptional stop cassette in front of membrane-anchored GFP (mGFP) integrated into the Tau locus (Hippenmeyer et al., 2005). Cre-mediated recombination can be detected by the expression of mGFP in the axons of recombined neurons. Dlx-mGFP mice (P15) or CB1R knock-out mice (P27) were deeply anesthetized and transcardially perfused with ice-cold PBS, pH 7.4, followed by $4 \%$ paraformaldehyde in PBS, $\mathrm{pH}$ 7.4. The brains were postfixed with the same fixative overnight at $4^{\circ} \mathrm{C}$. Brains were sectioned into $50-\mu \mathrm{m}$-thick sections with a vibrating microtome (Leica VT1000S) in the coronal plane. Free-floating sections were washed with PBST and permeabilized with $0.2 \%$ Triton X-100 in PBS at room temperature for $20 \mathrm{~min}$. Sections were then washed with PBST, blocked for $1 \mathrm{~h}$ with 3\% normal goat serum in PBST at room temperature, and then incubated with a mixture of two primary antibodies against CB1Rs (raised against the C terminus AA400-473 in guinea pig; 1.5 $\mu \mathrm{g} / \mathrm{ml}$, kindly provided by Dr. Ken Mackie, Indiana University, Bloomington, IN) and chicken anti-GFP (1:1000, Aves Labs) in PBST with $2 \mathrm{mg} / \mathrm{ml}$ $\mathrm{BSA}$ and $1 \%$ normal goat serum at $4^{\circ} \mathrm{C}$ overnight. Sections were then washed with PBST, and incubated with the fluorescent secondary antibodies: goat antiguinea pig IgG-Cy3 (Jackson ImmunoResearch Laboratories; 1:500); goat antichicken IgG-Alexa 488 (Invitrogen, 1:500) in PBST at room temperature for $2 \mathrm{~h}$. Following this incubation, sections were washed with PBST three times for 10 min each. Confocal images were obtained using a Zeiss 510 system.

\section{Results}

Target-dependent expression of DSI at two synapses formed by TRN cells

We investigated short-term changes in synaptic strength triggered by postsynaptic depolarization, at synapses formed by TRN neurons onto two postsynaptic targets, TRN neurons and relay cells in the VB. Cells were voltage clamped at $-70 \mathrm{mV}$ with a cesium-based internal solution, and synapses were activated at $0.3 \mathrm{~Hz}$ using stimulus electrodes placed in the TRN, before and following depolarization of the postsynaptic cell to $0 \mathrm{mV}$ for $5 \mathrm{~s}$. For TRN neurons, depolarization reduced the IPSC amplitude to $29.4 \pm 3.8 \%$ of control $(n=8)$ (Fig. $1 A, C)$. DSI was completely eliminated in the presence of the CB1R antagonist AM251 $(5 \mu \mathrm{M}$, $103.4 \pm 4.5 \%$ of baseline, $n=8$ ), indicating that it was mediated by endocannabinoid release from postsynaptic TRN neurons. By contrast, no DSI was observed at synapses targeting VB neurons $(97.3 \pm 3.0 \%$ of control), and bath application of AM251 $(5 \mu \mathrm{M})$ did not reveal changes in IPSC amplitudes following voltage steps $(94.7 \pm 1.5 \%$ of baseline in AM251) (Fig. $1 B, D)$. These data show that endocannabinoids regulate synaptic strength at TRN inhibitory synapses in a target-dependent manner.

TRN cells receive inhibitory inputs not only from local TRN neurons (Deleuze and Huguenard, 2006; Lam et al., 2006), but from other sources such as the basal forebrain, the globus pallidus, and the substantia nigra (Asanuma and Porter, 1990; Paré et al., 1990; Bickford et al., 1994; Govindaiah et al., 2010). Thus, evoking IPSCs in TRN neurons with stimulating electrodes 
placed in TRN could in principle activate different types of inhibitory synapses. We found that DSI was prominent for all cells recorded in TRN (range of reduction 9.8-52.2\% of control, $n=$ 8 ), suggesting that activated synapses had sensitivity similar to that of endocannabinoids, regardless of their possible origin. In an attempt to isolate synapses formed by TRN neurons, we placed stimulating electrodes in VB to activate presynaptic TRN neurons antidromically and to avoid the recruitment of other inhibitory afferents to TRN whose axons are not thought to pass through the thalamus. DSI was observed in all recordings for which IPSCs were activated antidromically ( $48.8 \pm 5.8 \%$ of control, $n=5$ cells), further indicating that endocannabinoid-mediated DSI is prominent at synapses interconnecting TRN neurons.

\section{Differential presynaptic effects of CB1R activation at TRN inhibitory synapses}

Next, we examined the mechanisms underlying the targetdependent DSI at TRN synapses. Previous studies have shown that differences in endocannabinoid-mediated plasticity can depend on presynaptic mechanisms, such as differences in CB1R expression levels (Ohno-Shosaku et al., 2002; Tzounopoulos et al., 2007) or mechanisms downstream of CB1R activation (Lee et al., 2010). In addition, differences in endocannabinoid signaling can be mediated by the differential ability of postsynaptic neurons to synthesize and release endocannabinoids (Beierlein et al., 2007). To characterize cannabinoid sensitivity at the two types of TRN synapses, we bath applied saturating doses of the CB1R agonist WIN 55,212 (WIN, $5 \mu \mathrm{M}$ ) and compared IPSC suppression between synapses targeting TRN and VB neurons. For intraTRN synapses, WIN decreased IPSC amplitudes to $29.8 \pm 4.0 \%$ of control, and this effect was reversed by the CB1R antagonist AM251 $(10 \mu \mathrm{M}, 103.2 \pm 5.2 \%$, $n=7$ ) (Fig. 2A,D). WIN application significantly increased paired-pulse ratio (control: $0.78 \pm 0.09$, WIN: $1.01 \pm 0.12$, $p<0.05$ ), which was reversed following bath application of AM251 (10 $\mu \mathrm{M}$, $0.76 \pm 0.05$ ) (Fig. 2C), consistent with a presynaptic expression of CB1Rs. As summarized in Figure $2 D$, the IPSC reduction following WIN application was comparable to the amplitude reduction during DSI, indicating that endocannabinoids released from TRN neurons can completely saturate presynaptic CB1Rs.

For VB neurons, we found that WIN (5 $\mu \mathrm{M})$ also led to a reduction of the IPSC amplitude, although the magnitude of suppression was significantly smaller than in TRN neurons (WIN: $58.0 \pm 3.2 \%$ of control, AM251: $93.8 \pm 2.2 \%$ of control, $n=7$ ) (Fig.

$2 B, F)$. Paired-pulse ratio increased from $0.67 \pm 0.05$ to $0.79 \pm$ 0.04 after application of WIN $(p<0.05)$ and returned to control levels following AM251 application (0.65 \pm 0.04 ) (Fig. 2E). Thus, $\mathrm{CB1}$ Rs are expressed on inhibitory synaptic terminals targeting VB cells. However, their activation leads to a smaller reduction in synaptic strength and to a smaller change in paired-pulse ratio
A

TRN

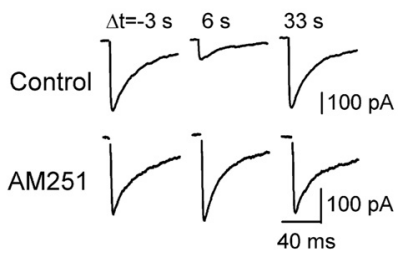

B
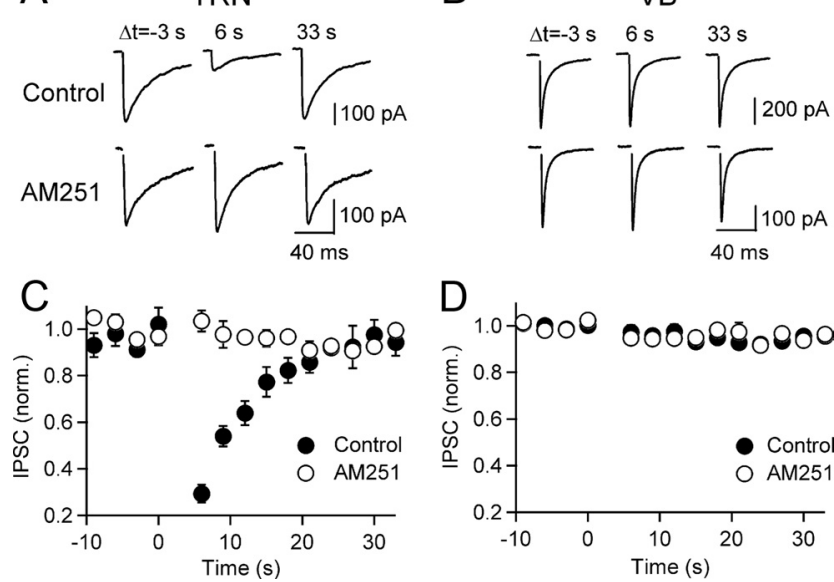

Figure 1. Target-specific DSI at TRN synapses. At time $t=0$, neurons were depolarized from -70 to $0 \mathrm{mV}$ for 5 s. $A, B$, Average responses of representative experiments are shown before $(\Delta t=-3 \mathrm{~s})$ and 6 and $33 \mathrm{~s}$ after the beginning of the postsynaptic depolarization for control conditions (top) and in the presence of the CB1R antagonist AM251 (5 $\mu \mathrm{M}$, bottom) for TRN ( $\boldsymbol{A}$ ) and VB neurons $(\boldsymbol{B})$. $\boldsymbol{C}, \boldsymbol{D}$, Summaries of the DSI time course are shown for control conditions (closed symbols, $n=8$ ) and in the presence of AM251 ( $5 \mu \mathrm{m}$, open symbols, $n=8)$ for TRN ( $C$ and VB neurons $(\boldsymbol{D})$. Data are expressed as mean \pm SEM.
A
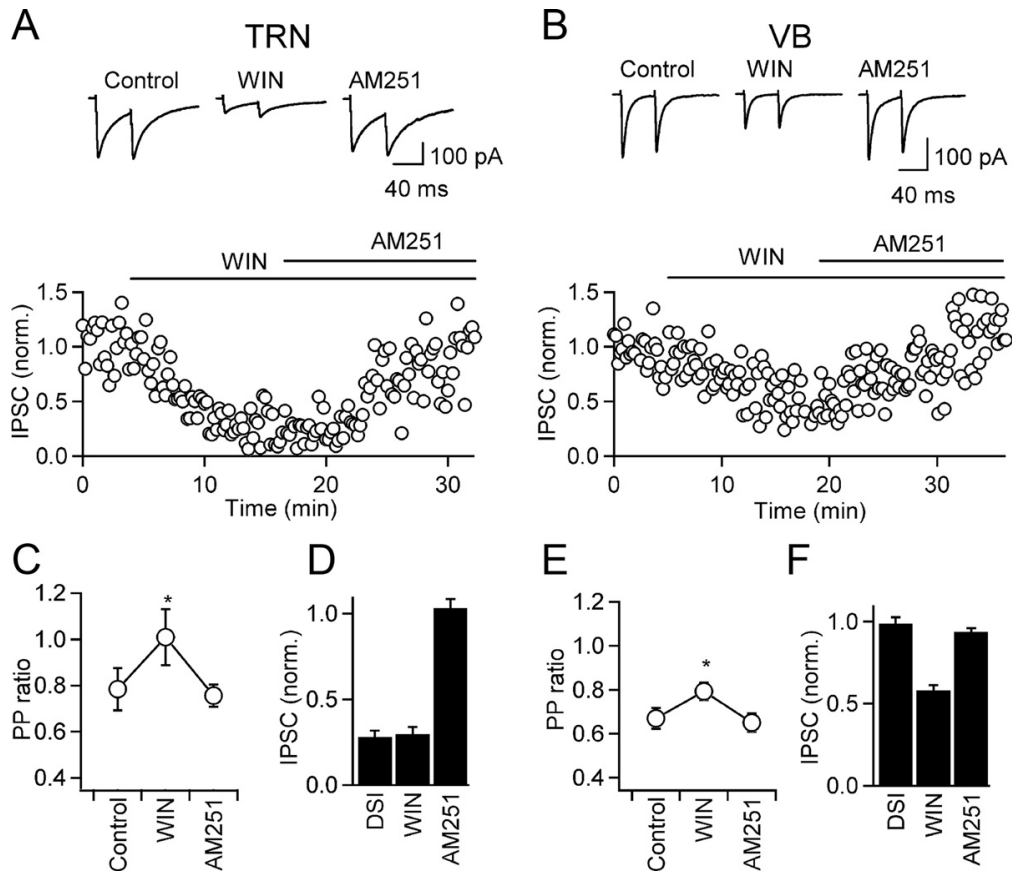

Figure 2. Presynaptic expression of CB1Rs at inhibitory synapses in TRN and VB. Inhibitory synapses were activated with paired pulses $(50 \mathrm{~ms} \mid \mathrm{SI})$. $\boldsymbol{A}, \boldsymbol{B}$, Representative experiments are shown for TRN $(\boldsymbol{A})$ and VB $(\boldsymbol{B})$. Top, Average paired-pulse responses in control conditions, followed by bath application of the CB1R agonist WIN 55,212-2 (WIN, $5 \mu \mathrm{M}$ ) and the CB1R antagonist AM251 $(10 \mu \mathrm{m})$. Bottom, IPSC amplitude (normalized to control) plotted as a function of time. $\boldsymbol{C}, \boldsymbol{E}$, Summary of the changes in the average IPSC paired-pulse ratio (IPSC $/$ /PSC $)$, for responses recorded in $\operatorname{TRN}\left(\boldsymbol{C}, n=7,{ }^{*} p<0.05\right.$, paired Student's $t$ test) and VB $(\boldsymbol{E}, n=$ $7,{ }^{*} p<0.05$, paired Student's $t$ test). $\boldsymbol{D}, \boldsymbol{F}$, Summary of the average IPSC amplitude (normalized to their respective control) during $\operatorname{DSI}(\Delta t=6 \mathrm{sin}$ Fig. 1), following WIN application, and following WIN + AM251 application, for responses in TRN (D) and VB $(\boldsymbol{F})$. than does CB1R activation on intra-TRN synapses, a result consistent with target-dependent differences in cannabinoid sensitivity at TRN synapses.

Synaptic strength at corticothalamic synapses is partially reduced by endocannabinoid release from VB neurons

Our data above suggest that presynaptic specializations alone could explain target-dependent endocannabinoid signaling at 

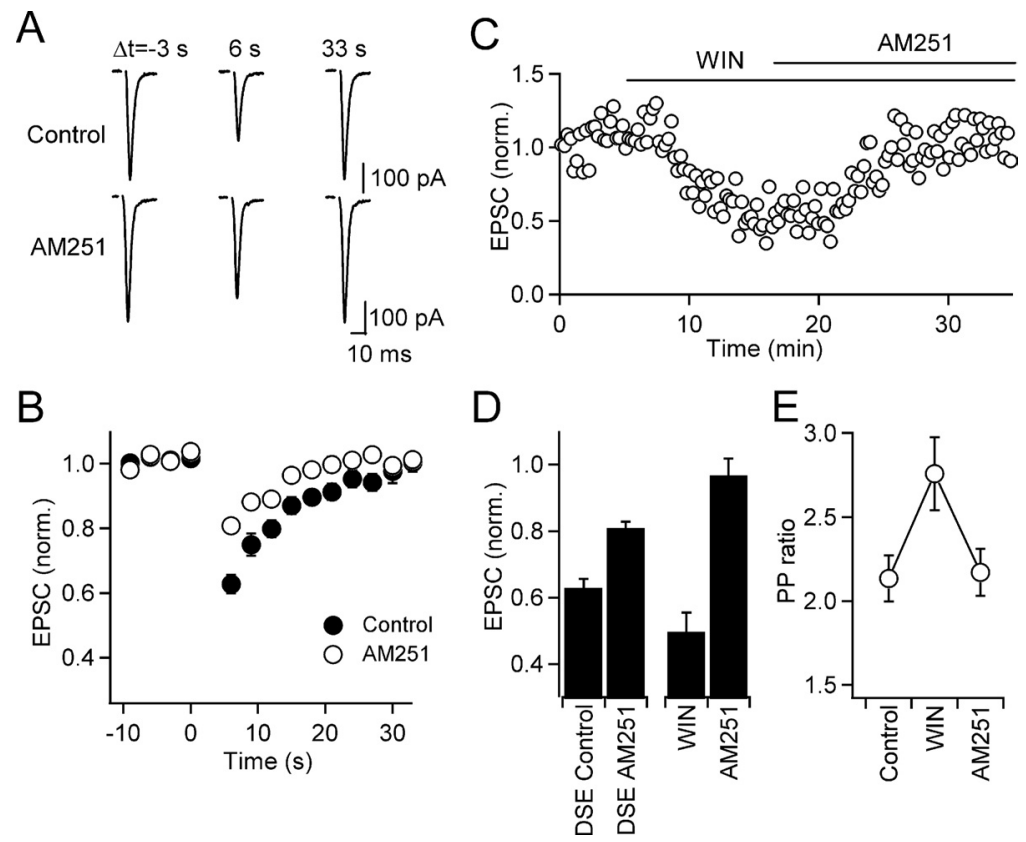

Figure 3. DSE at corticothalamic synapses. $A$, A representative experiment showing CT EPSCs before and after a $5 \mathrm{~s}$ depolarization step to $0 \mathrm{mV}$ in control conditions and in AM251 (5 $\mu \mathrm{M})$. $\boldsymbol{B}$, Summary data for the time course of DSE at the CT synapses, in control (closed symbols) and in AM251 (5 $\mu \mathrm{M}$, open symbols), $n=7-8$ cells. C, A representative experiment plotting CT EPSC amplitude (normalized to control), before and during bath application of WIN (5 $\mu \mathrm{M})$ and AM251 (10 $\mu \mathrm{M})$. D, Summary data for CT EPSC amplitude (normalized to respective control values) during DSE (in control and following application of AM251), following WIN application, and following AM251 application, $n=6-8$. $\boldsymbol{E}$, Summary data of changes in paired-pulse ratio following bath application of WIN $(5 \mu \mathrm{M})$ and AM251 $(10 \mu \mathrm{M}) . n=6,{ }^{*} p<0.05$, paired Student's $t$ test.

TRN synapses. Alternatively, the absence of DSI in VB could be due to a lack of endocannabinoid synthesis and release in VB neurons under our experimental conditions. As a consequence, depolarization-induced suppression of synaptic strength should not be observed at any synaptic input targeting VB neurons. We examined this possibility by characterizing endocannabinoid signaling at glutamatergic corticothalamic (CT) synapses, formed by neocortical layer 6 neurons. Stimulating electrodes were placed in the internal capsule or TRN, and CT synapses were activated in the presence of picrotoxin, CGP 55845, and R-CPP to block $\mathrm{GABA}_{\mathrm{A}}, \mathrm{GABA}_{\mathrm{B}}$, and NMDA receptors, respectively. We found that postsynaptic depolarization led to a moderate reduction in CT EPSC amplitude, which was partially eliminated by AM251 (control, $62.8 \pm 2.8 \%$; AM251, $80.8 \pm 1.9 \%, n=7-8, p<0.05$ ) (Fig. $3 A, B$ ), indicating that relay neurons have the ability to synthesize and release endocannabinoids. Application of WIN (5 $\mu \mathrm{M})$ significantly reduced EPSC amplitudes (49.6 $\pm 5.7 \%$ of control) (Fig. $3 C, D$ ) and increased PPR (control, $2.13 \pm 0.13$; WIN, $2.75 \pm$ 0.22 ) (Fig. $3 E$ ), and both returned to control levels following bath application of AM251 ( $10 \mu \mathrm{M}, 96.7 \pm 5.1 \%$ for EPSC, $2.17 \pm 0.14$ for PPR).

Together, our data show that VB neurons can synthesize and release endocannabinoids in a calcium-dependent manner, making it unlikely that the lack of DSI can be entirely attributed to a general absence of endocannabinoid release from VB neurons.

\section{Tissue-specific differences in CB1R expression}

Thus far, our data showing stronger DSI and WIN-induced suppression of synaptic strength at intra-TRN synapses are consistent with a higher overall expression of presynaptic cannabinoid receptors in TRN than in VB. Previous studies using CB1R ligand autoradiography (Herkenham et al., 1991; Mailleux and Vander- haeghen, 1992) or immunohistochemical labeling of CB1Rs (Marsicano and Lutz, 1999) have revealed only low levels of expression of CB1Rs in thalamic nuclei or TRN. To independently verify the existence of CB1Rs in thalamic circuits and to reveal potential differences in CB1R expression between TRN and VB, we performed immunostaining for CB1Rs in dlx-mGFP mice that express membrane GFP specifically in inhibitory terminals (Fig. 4Aa1-Ae1). Consistent with our electrophysiological data, overall levels of CB1R immunostaining were higher in TRN compared to VB (Fig. 4Aa2-Ae2). Furthermore, CB1R immunostaining correlated with GFP staining, consistent with a preferential targeting of CB1Rs to inhibitory neurons (Fig. 4Aa3-Ae3,Af1-Af3) (Monory et al., 2007). Notably, this held true for the lateral geniculate nucleus (LGN), which in contrast to VB contains local interneurons, and showed high levels of CB1R expression (Fig. 4Aa2). No immunostaining was detected in $\mathrm{CB} 1 \mathrm{R}$ $\mathrm{KO}$ animals (Fig. $4 A g-A i$ ). Together, our immunohistochemical data confirm that CB1Rs are expressed at inhibitory synapses in TRN and suggest that retrograde signaling via endocannabinoids is expressed in other sensory thalamic nuclei.

\section{DSI is absent in CB1R knock-out mice}

To further confirm that DSI observed in TRN cells is mediated by presynaptic CB1Rs, we performed DSI experiments in slices of CB1R knock-out animals (Marsicano et al., 2002) and their wildtype littermates. DSI was completely abolished in CB1R knockout mice $(100.9 \pm 3.4 \%, n=7)$, compared with WT animals (32.5 $\pm 5.4 \%, p<0.01, n=7)$ (Fig. $4 B$ ). Additionally, WIN (5 $\mu \mathrm{M})$ had no effect on the IPSC amplitude in CB1R knock-out mice ( $99.9 \%$ of control, $n=6$ ) compared to wild-type controls (33.6\% of control, $n=5$ ) (Fig. $4 C$ ). These results confirm that retrograde inhibition at TRN neurons is indeed mediated by presynaptic CB1Rs.

\section{DSI in the TRN is mediated by the calcium-dependent release} of 2-AG from the postsynaptic cell

A number of different types of endocannabinoids can potentially be released from postsynaptic neurons (Best and Regehr, 2010; Min et al., 2010; Tanimura et al., 2010). Two of the most common endocannabinoid messengers are 2-AG and anandamide. Distinct pathways are involved in the synthesis and breakdown of each messenger, so their biological role can differ dramatically (Long et al., 2009b), thus highlighting the importance of identifying the endocannabinoid being released from TRN neurons. Pharmacological studies at inhibitory hippocampal synapses have suggested that 2-AG is not involved in mediating DSI (Chevaleyre and Castillo, 2003; Edwards et al., 2006; Min et al., 2010). In apparent conflict with these data, no DSI was observed in the same preparation using mutant mice lacking DAGL $\alpha$, the synthesizing enzyme for 2-AG (Gao et al., 2010; Tanimura et al., 2010). We found that DSI was abolished by the inclusion of BAPTA (20 mM) to the recording solution (Fig. 5B), confirming 
A
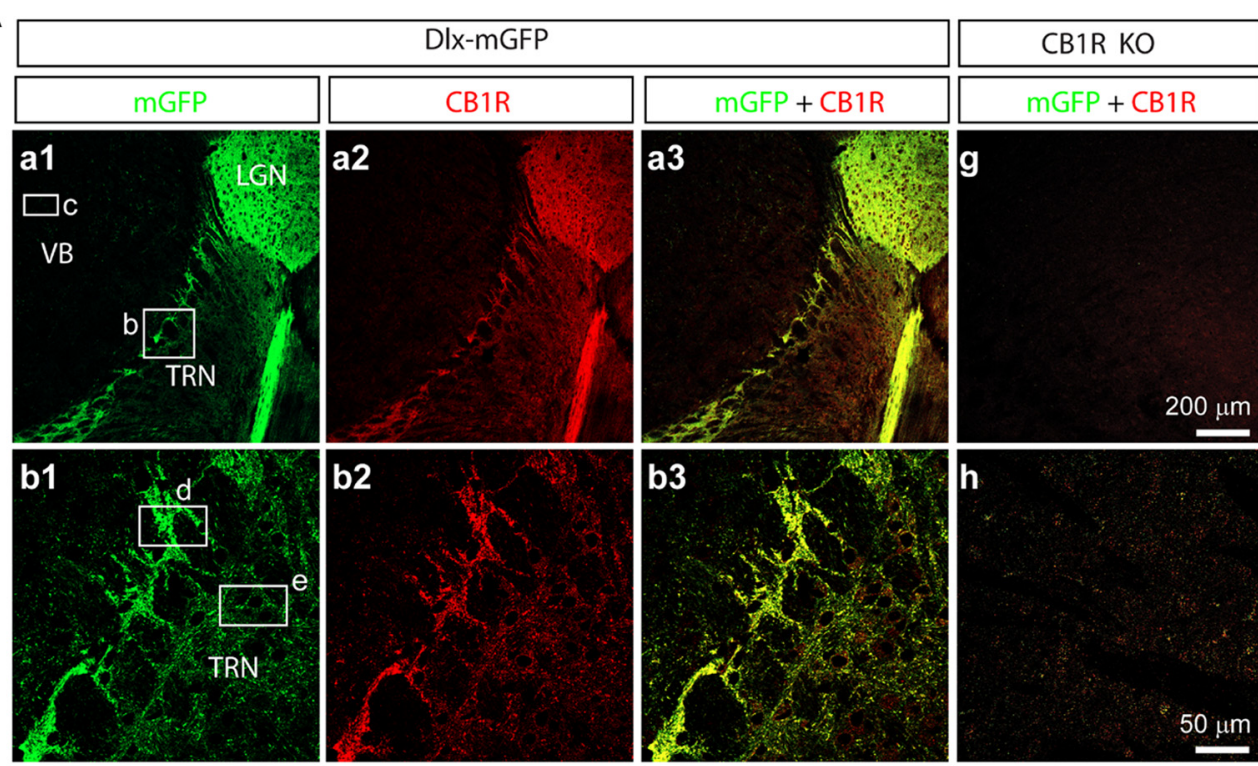

g
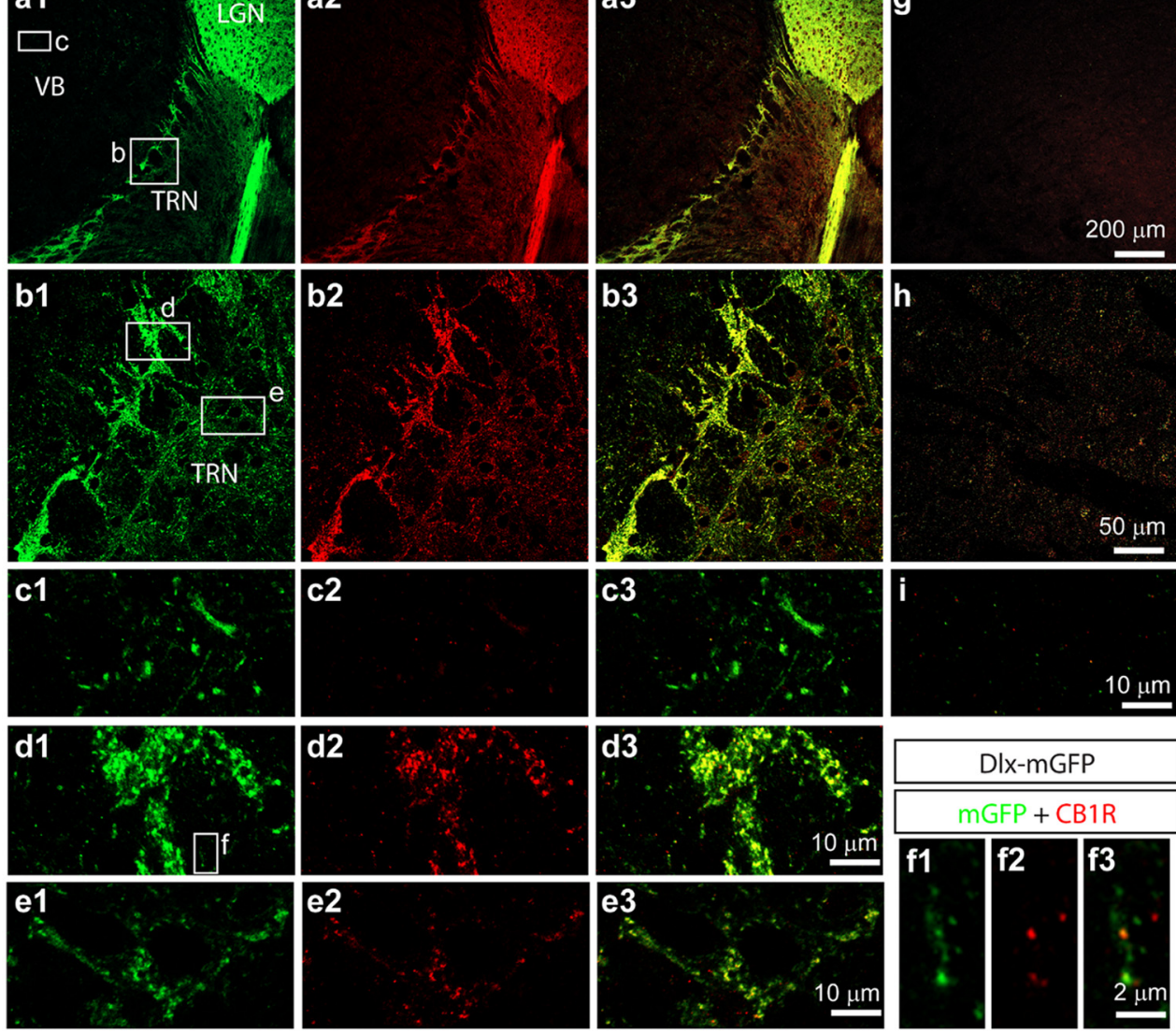

e2

B
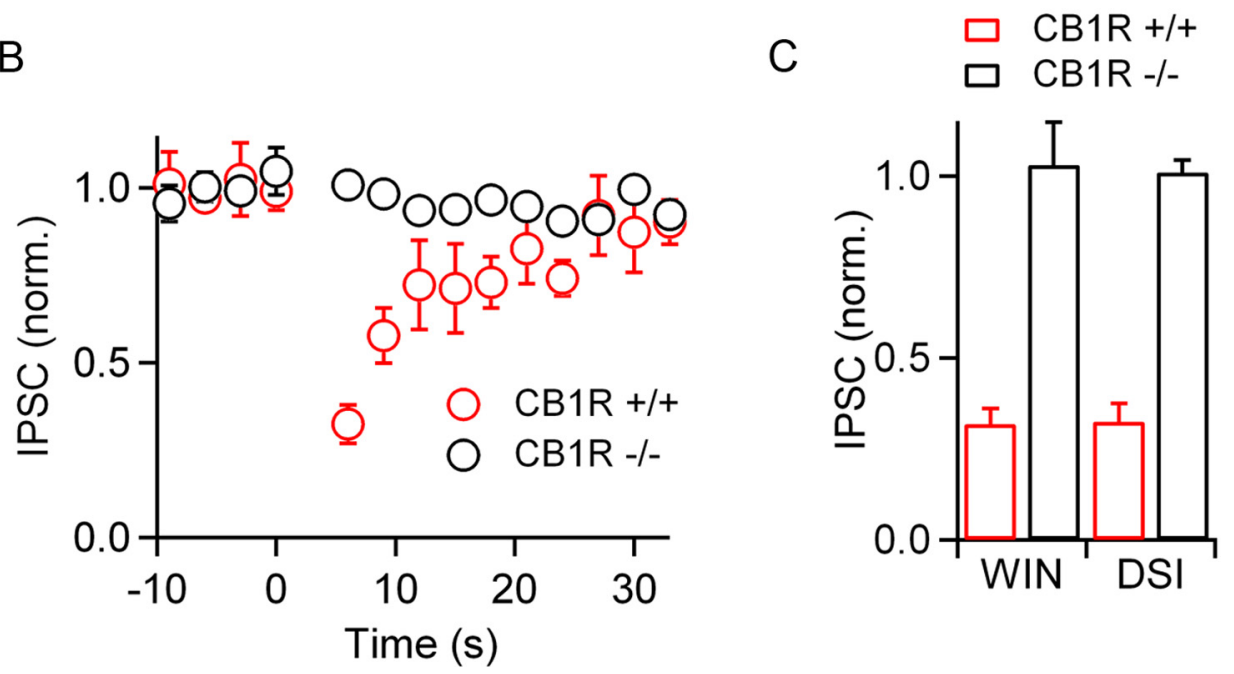

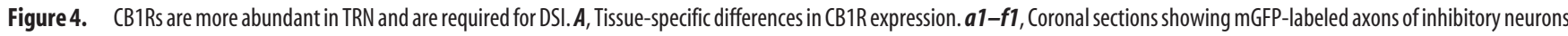
in the VB and TRN in dlx-mGFP reporter mice. $\boldsymbol{b} 1$ shows area near the TRN-VB border indicated in $\boldsymbol{a} 1 . \boldsymbol{a} 2-f 2$, CB1R expression in same sections. $\boldsymbol{a} 3-\mathbf{f 3}$, Overlay. $\mathbf{c}-\boldsymbol{e}$, Higher-magnification view of the squared areas indicated in $\boldsymbol{a} 1$ and $\boldsymbol{b}$ 1. $\boldsymbol{f}$, Higher-magnification view of the area indicated in $\boldsymbol{d 1}$, showing colocalization of CB1R- and mGFP-immunoreactive signals in vesicular-like structures. $\boldsymbol{g}-\boldsymbol{i}$, Coronal sections show absence of (B1R and GFP immunoreactivity in a CB1R knock-out mouse. B, C, DSl at intra-TRN synapses is mediated by CB1Rs. B, Summary of DSI time course in wild-type (red symbols) and CB1R knock-out (black symbols) mice. C, Summary of the average IPSC amplitude (normalized to their respective control) following WIN application and during DSI $(\Delta t=6 \mathrm{~s}$ ), for wild-type and CB1R knock-out mice.

the calcium dependence of endocannabinoid release. In addition, DSI was significantly decreased in the presence of the DAGL inhibitor RHC80267 (RHC, $30 \mu \mathrm{M}$ ) as compared to control (Fig. $5 B$ ) (control, $29.4 \pm 3.8 \%, n=8$; RHC, $86.4 \pm 5.2 \%, n=6$; $p<$
0.001), suggesting that 2-AG is the active endocannabinoid released by TRN neurons. Similarly, DSI was attenuated by including the DAGL inhibitor THL $(5 \mu \mathrm{M})$ in the patch pipette (Fig. $5 A, B)(83.6 \pm 5.5 \%, n=6, p<0.001)$. Once released, $2-A G$ is 

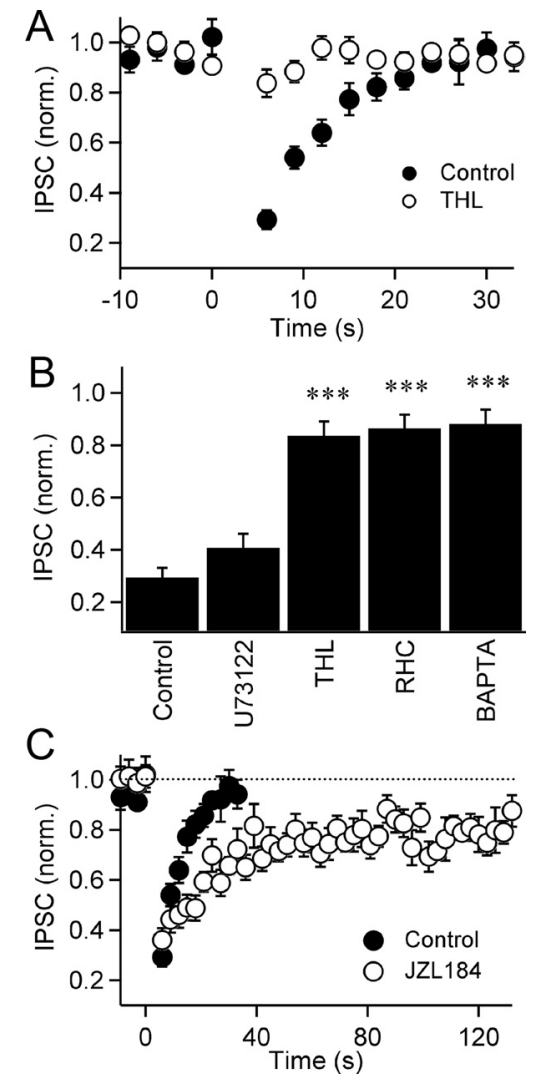

Figure 5. 2-AG is released from TRN neurons during DSI. $A$, Time course of DSI under control conditions (data as in Fig. 1C) and with the DAGL inhibitor THL (5 $\mu \mathrm{M}$, open symbols, $n=6$ ) in the recording pipette. $B, D S I$ (measured as IPSC amplitude at $\Delta t=6 \mathrm{~s}$, normalized to the amplitude before the depolarizing step) recorded in control conditions, in the presence of the phospholipase C inhibitor U73122 ( $5 \mu \mathrm{m}$, bath applied for $1 \mathrm{~h}$ ), in the presence of the DAGL inhibitor THL, in the presence of the DAGL inhibitor RHC80267 in the bath $(30 \mu \mathrm{M})$, and with calcium buffer BAPTA (20 mm) in the recording pipette. $n=5-7$ cells for each condition $\left({ }^{* * *} p<0.001\right.$, unpaired Student's $t$ test). C, Time course of DSI is prolonged in the presence of the monoacylglycerol lipase inhibitor JZL $184(100 \mathrm{~nm}$, open symbols, $n=7)$ compared to control (closed symbols, $n=8$ ). RHC, RHC80267.
A

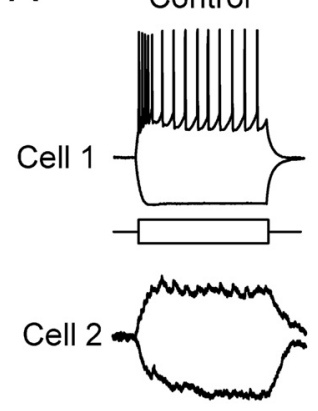

WIN

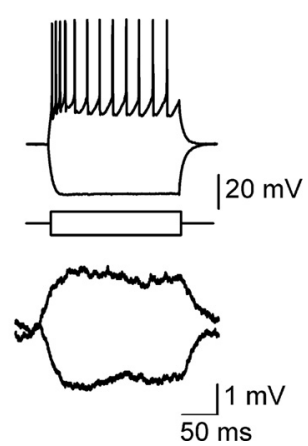

\section{B}

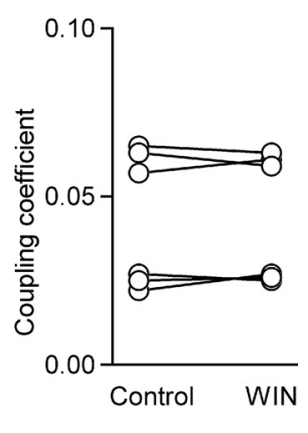

Figure 6. Electrical synapses in TRN are not regulated by endocannabinoids. $\boldsymbol{A}$, Simultaneous current-clamp recordings from two neighboring TRN neurons. Depolarizing and hyperpolarizing current steps $( \pm 300 \mathrm{pA})$ were injected to cell 1 only, in control conditions (left) and following bath application of WIN55,212 (WIN, $5 \mu \mathrm{M}$, right). $\boldsymbol{B}$, Summary of changes in coupling coefficient following WIN application ( $n=6, p=0.83$, paired Student's $t$ test). Coupling coefficient was determined as $V_{2} / V_{1}$, where $V_{1}$ refers to the potential change of the current-injected cell and $V_{2}$ is the potential change of the other cell.

broken down by the enzyme monoacylglycerol lipase (MGL). Therefore, if 2-AG is released TRN neurons, blocking its breakdown should lead to a slower recovery of DSI. Consistent with this idea, incubating slices with the MGL inhibitor JZL184 (Long et al., 2009a; Pan et al., 2009) significantly prolonged the duration of DSI (Fig. $5 C)\left(\tau_{\text {decay }}=9.3 \pm 2.0 \mathrm{~s}\right.$ in control, $24.9 \pm 3.6 \mathrm{~s}$ in JZL184, $n=7-8, p<0.01)$.

Our data show that calcium increases in the postsynaptic neuron are sufficient to trigger the synthesis and release of 2-AG. Release of 2-AG also occurs following the activation of $\mathrm{G}_{\mathrm{q} / 11^{-}}$ coupled receptors acting on phospholipase C (PLC), resulting in the activation of DAGL (Brown et al., 2003; Melis et al., 2004; Hashimotodani et al., 2005; Maejima et al., 2005). As PLC activation is dependent on both calcium increases and $\mathrm{G}_{\mathrm{q} / 11}$-coupled receptor activation, the magnitude of DSI at intra-TRN synapses could in part be determined by the constitutive activation of $\mathrm{G}_{\mathrm{q} / 11}$-coupled receptors by ambient levels of neurotransmitters. To test this possibility, we evoked DSI in the presence of the PLC inhibitor U73122 (5 $\mu \mathrm{M})$ (Fig. 5B). We found that DSI was indistinguishable from control ( $40.7 \pm 5.4 \%, n=6, p=0.15)$, suggesting that $2-\mathrm{AG}$ release is not facilitated by the activation of PLC. Together, our results indicate that DSI at intra-TRN synapses is evoked by the calcium-dependent release of 2-AG, independent of PLC activation.

\section{CB1R activation does not influence electrical coupling between TRN neurons}

In addition to being interconnected by chemical synapses, neurons in the TRN are strongly coupled by electrical synapses, formed by channels composed of connexin 36 (Landisman et al., 2002). Previous work has demonstrated that the activation of postsynaptic mGluRs can regulate coupling strength at electrical synapses (Landisman and Connors, 2005). To test whether the endocannabinoid-mediated regulation of synaptic strength extends to electrical synapses (Venance et al., 1995; Cachope et al., 2007), we performed dual recordings from neighboring TRN neurons using a potassium-based internal solution and measured electrical coupling strength in current clamp, before and after bath application of the CB1R agonist WIN $(5 \mu \mathrm{M})$ (Fig. 6A). We found that WIN had no effect on electrical coupling between TRN neurons (coupling coefficient $=0.043 \pm 0.008$ in control, $0.044 \pm 0.008$ in WIN, $n=6, p=0.83$ ) (Fig. $6 B$ ).

The expression of CB1Rs is not always restricted to synaptic terminals. Activation of CB1Rs in specific types of interneurons in neocortex (Bacci et al., 2004) and the cerebellum (Kreitzer et al., 2002) is linked to opening of postsynaptic potassium conductances, resulting in short- or long-lasting forms of membrane hyperpolarization. We found that the application of WIN $(5 \mu \mathrm{M})$ did not cause significant changes in membrane resting potential (control $71.7 \pm 0.8 \mathrm{mV}$, WIN $72.3 \pm 1.4 \mathrm{mV}, n=6, p=0.84$ ), suggesting that TRN neurons do not express postsynaptic CB1Rs. Thus, endocannabinoids released from TRN appear to act specifically to reduce synaptic strength at chemical synapses.

\section{Discussion}

Our study provides the first direct demonstration of endocannabinoidmediated synaptic plasticity in the thalamus. Specifically, we have shown that DSI is prominent at inhibitory synapses formed onto TRN neurons, mediated by the calcium-dependent synthesis and 
release of the endocannabinoid 2-AG. By contrast, no DSI was observed at inhibitory synapses targeting VB cells. Our electrophysiological and immunohistochemical data indicate that target-dependent endocannabinoid signaling is mediated at least in part by differences in presynaptic endocannabinoid sensitivity at the two types of inhibitory terminals. As intra-TRN inhibitory synapses are thought to be critical in limiting oscillatory activity in thalamic circuits (Beenhakker and Huguenard, 2009), our results suggest that endocannabinoid release could enhance physiological levels of thalamic synchrony as observed during sleep spindles, but might also regulate the threshold for the generation of seizure-like activity (van Rijn et al., 2010).

\section{Target-dependent modulation of synaptic inhibition by endocannabinoids}

Our results show, for the first time, that cannabinoid signaling at inhibitory synapses is regulated in a target-dependent manner and is mediated by synapse-specific differences in endocannabinoid sensitivity. Previous findings at excitatory parallel fiber synapses in the dorsal cochlear nucleus have revealed that the target-cell-dependent expression of presynaptic CB1Rs can underlie both short- and long-term forms of synaptic plasticity (Tzounopoulos et al., 2007). Thus, the simplest explanation for our results is that the densities of CB1Rs at synaptic terminals formed by TRN neurons vary in a target-cell-dependent manner. Consistent with this idea, some studies have shown a tight correlation between CB1R expression levels and endocannabinoid sensitivity (Kawamura et al., 2006; Tzounopoulos et al., 2007). However, presynaptic CB1R expression does not always predict sensitivity to endocannabinoids (Kawamura et al., 2006; Lee et al., 2010). Thus, it is possible that the intracellular pathway downstream of CB1R activation varies for distinct synaptic terminals and effectively controls endocannabinoid-mediated reductions in transmitter release.

The target dependence of endocannabinoid signaling we have characterized for TRN synapses could also be mediated postsynaptically. In the cerebellar cortex, parallel fiber synapses formed onto different postsynaptic targets display similar sensitivity for exogenous ligands, but show strong differences in endocannabinoid-mediated DSE, suggesting that the ability of neurons to synthesize and release endocannabinoids can vary along distinct cell types (Beierlein et al., 2007). Here we found that while DSI was not observed for inhibitory synapses onto VB neurons, excitatory corticothalamic synapses targeting the same cell type displayed endocannabinoid-mediated DSE. Thus, excluding the possibility of synapse-specific endocannabinoid release from VB neurons following depolarization, the complete absence of DSI in VB cannot be explained by a general absence of endocannabinoid synthesis and release from postsynaptic VB neurons. As of now, it is not possible to directly measure endocannabinoid release from neurons, leaving the contribution of postsynaptic mechanisms in regulating synapse-specific differences at TRN synapses unresolved. Work in hippocampal cultures has shown that the differences in depolarization-induced suppression at inhibitory and excitatory synapses can be mimicked by the same subsaturating dose of exogenous CB1R ligand, suggesting that presynaptic sensitivity is a major determinant of endocannabinoid-mediated signaling (Ohno-Shosaku et al., 2002). However, due to the lipophilic nature of the CB1R agonists, such an approach is impractical in acute brain slices (Brown et al., 2004) and was not further pursued here.

In summary, our results indicate that presynaptic differences in endocannabinoid sensitivity underlie target-dependent differ- ences in endocannabinoid signaling at TRN synapses, although we cannot rule out differences in endocannabinoid release from the two types of target neurons.

\section{Pathways leading to the release of endocannabinoids during DSI}

Pharmacological and genetic studies have led to conflicting data regarding the mechanisms underlying endocannabinoid synthesis and release during DSI (Di Marzo, 2011). Here we found that blocking 2-AG synthesis with two different inhibitors of DAGL largely eliminated DSI. In addition, blocking 2-AG degradation by inhibiting monoacylglycerol lipase led to a prolongation of the DSI time course. Together, our data show that DSI at intra-TRN synapses is mediated by the release of 2-AG. This agrees with recent studies using DAGL $\alpha$ knock-out animals (Gao et al., 2010; Tanimura et al., 2010), which confirmed that 2-AG is the major endocannabinoid responsible for retrograde signaling in the hippocampus, the cerebellum, and the striatum. While the pathway leading from postsynaptic calcium increases to the activation of DGL $\alpha$ and synthesis of 2-AG during DSI or DSE is still unresolved (Best and Regehr, 2010), studies at synapses throughout the CNS have established that 2-AG synthesis and release can also occur following activation of a number of $\mathrm{G}_{\mathrm{q} / 11}$ protein-coupled receptors expressed in the postsynaptic membrane, which triggers the activation of PLC $\beta$, the production of DAG, and the synthesis of 2-AG by DAGL (Brown et al., 2003; Melis et al., 2004; Brenowitz and Regehr, 2005; Hashimotodani et al., 2005; Maejima et al., 2005; Kano et al., 2009). Importantly, PLC activation can be augmented by moderate, physiologically realistic increases in postsynaptic calcium (Hashimotodani et al., 2005). The importance of receptor-driven endocannabinoid release (RER) is emphasized by the close subcellular association between $G_{q / 11}$ protein-coupled receptors, PLC, and DAGL in postsynaptic dendrites or spines (Katona et al., 2006; Yoshida et al., 2006). TRN neurons express a number of different types of $\mathrm{G}_{\mathrm{q} / 11}$ proteincoupled receptors, suggesting that RER might be a prominent pathway of endocannabinoid release under physiological conditions. Furthermore, RER could be enhanced during dendritic calcium increases via T-type calcium channel activation, evoked by burst firing (Cueni et al., 2008; Crandall et al., 2010) or synaptic activation (Crandall et al., 2010).

\section{Endocannabinoid signaling and the regulation of thalamic synchrony}

Our results demonstrating endocannabinoid-dependent regulation of synaptic strength at specific inhibitory thalamic pathways strongly suggest that endocannabinoids dynamically regulate the degree of thalamic synchrony. Experimental and computational studies suggest that the two types of inhibitory synapses formed by TRN neurons onto either VB neurons or neighboring TRN neurons have opposing roles in regulating the degree of thalamic synchrony (Beenhakker and Huguenard, 2009). Inhibitory synapses formed by TRN neurons onto VB cells are a crucial component of the reciprocally connected TRN-VB circuit that can generate rhythmic oscillations, even in the absence of extrinsic inputs. By contrast, intra-TRN synapses are thought to be important for reducing activity in neighboring TRN neurons (Bal et al., 1995), thereby limiting the number TRN neurons that participate in rhythmic oscillatory activity (Sanchez-Vives and McCormick, 1997; Sohal and Huguenard, 2003). In support of this hypothesis, pharmacological or genetic elimination of intra-TRN inhibition can lead to hypersynchronous activity patterns in vivo (CastroAlamancos, 1999) as well as in in vitro models (von Krosigk et al., 
1993; Huguenard and Prince, 1994; Kim et al., 1997). Under these assumptions, our results predict that endocannabinoidmediated suppression of synaptic strength at intra-TRN synapses dynamically increases the degree of thalamic synchrony and therefore plays a critical role in setting the threshold for the generation of absence seizure activity.

\section{References}

Agmon A, Connors BW (1991) Thalamocortical responses of mouse somatosensory (barrel) cortex in vitro. Neuroscience 41:365-379.

Asanuma C, Porter LL (1990) Light and electron microscopic evidence for a GABAergic projection from the caudal basal forebrain to the thalamic reticular nucleus in rats. J Comp Neurol 302:159-172.

Bacci A, Huguenard JR, Prince DA (2004) Long-lasting self-inhibition of neocortical interneurons mediated by endocannabinoids. Nature 431:312-316.

Bal T, von Krosigk M, McCormick DA (1995) Role of the ferret perigeniculate nucleus in the generation of synchronized oscillations in vitro. J Physiol 483:665-685.

Beenhakker MP, Huguenard JR (2009) Neurons that fire together also conspire together: is normal sleep circuitry hijacked to generate epilepsy? Neuron 62:612-632.

Beierlein M, Fioravante D, Regehr WG (2007) Differential expression of posttetanic potentiation and retrograde signaling mediate targetdependent short-term synaptic plasticity. Neuron 54:949-959.

Best AR, Regehr WG (2010) Identification of the synthetic pathway producing the endocannabinoid that mediates the bulk of retrograde signaling in the brain. Neuron 65:291-292.

Bickford ME, Günlük AE, Van Horn SC, Sherman SM (1994) GABAergic projection from the basal forebrain to the visual sector of the thalamic reticular nucleus in the cat. J Comp Neurol 348:481-510.

Brenowitz SD, Regehr WG (2005) Associative short-term synaptic plasticity mediated by endocannabinoids. Neuron 45:419-431.

Brown SP, Brenowitz SD, Regehr WG (2003) Brief presynaptic bursts evoke synapse-specific retrograde inhibition mediated by endogenous cannabinoids. Nat Neurosci 6:1048-1057.

Brown SP, Safo PK, Regehr WG (2004) Endocannabinoids inhibit transmission at granule cell to Purkinje cell synapses by modulating three types of presynaptic calcium channels. J Neurosci 24:5623-5631.

Buzsáki G (2006) Rhythms of the brain. Oxford; New York: Oxford UP.

Cachope R, Mackie K, Triller A, O'Brien J, Pereda AE (2007) Potentiation of electrical and chemical synaptic transmission mediated by endocannabinoids. Neuron 56:1034-1047.

Castro-Alamancos MA (1999) Neocortical synchronized oscillations induced by thalamic disinhibition in vivo. J Neurosci 19:RC27.

Chevaleyre V, Castillo PE (2003) Heterosynaptic LTD of hippocampal GABAergic synapses: a novel role of endocannabinoids in regulating excitability. Neuron 38:461-472.

Crandall SR, Govindaiah G, Cox CL (2010) Low-threshold $\mathrm{Ca}^{2+}$ current amplifies distal dendritic signaling in thalamic reticular neurons. J Neurosci 30:15419-15429.

Cruikshank SJ, Landisman CE, Mancilla JG, Connors BW (2005) Connexon connexions in the thalamocortical system. Prog Brain Res 149:41-57.

Cueni L, Canepari M, Luján R, Emmenegger Y, Watanabe M, Bond CT, Franken P, Adelman JP, Lüthi A (2008) T-type Ca2+ channels, SK2 channels and SERCAs gate sleep-related oscillations in thalamic dendrites. Nat Neurosci 11:683-692.

Deleuze C, Huguenard JR (2006) Distinct electrical and chemical connectivity maps in the thalamic reticular nucleus: potential roles in synchronization and sensation. J Neurosci 26:8633-8645.

Di Marzo V (2011) Endocannabinoid signaling in the brain: biosynthetic mechanisms in the limelight. Nat Neurosci 14:9-15.

Edwards DA, Kim J, Alger BE (2006) Multiple mechanisms of endocannabinoid response initiation in hippocampus. J Neurophysiol 95:67-75.

Gao Y, Vasilyev DV, Goncalves MB, Howell FV, Hobbs C, Reisenberg M, Shen R, Zhang MY, Strassle BW, Lu P, Mark L, Piesla MJ, Deng K, Kouranova EV, Ring RH, Whiteside GT, Bates B, Walsh FS, Williams G, Pangalos MN, Samad TA, Doherty P (2010) Loss of retrograde endocannabinoid signaling and reduced adult neurogenesis in diacylglycerol lipase knock-out mice. J Neurosci 30:2017-2024.

Govindaiah G, Wang T, Gillette MU, Crandall SR, Cox CL (2010) Regula- tion of inhibitory synapses by presynaptic $\mathrm{D}$ dopamine receptors in thalamus. J Neurophysiol 104:2757-2765.

Hashimotodani Y, Ohno-Shosaku T, Tsubokawa H, Ogata H, Emoto K, Maejima T, Araishi K, Shin HS, Kano M (2005) Phospholipase Cbeta serves as a coincidence detector through its $\mathrm{Ca} 2+$ dependency for triggering retrograde endocannabinoid signal. Neuron 45:257-268.

Herkenham M, Lynn AB, Johnson MR, Melvin LS, de Costa BR, Rice KC (1991) Characterization and localization of cannabinoid receptors in rat brain: a quantitative in vitro autoradiographic study. J Neurosci 11:563-583.

Hippenmeyer S, Vrieseling E, Sigrist M, Portmann T, Laengle C, Ladle DR, Arber S (2005) A developmental switch in the response of DRG neurons to ETS transcription factor signaling. PLoS Biol 3:e159.

Huguenard JR (1996) Low-threshold calcium currents in central nervous system neurons. Annu Rev Physiol 58:329-348.

Huguenard JR, McCormick DA (2007) Thalamic synchrony and dynamic regulation of global forebrain oscillations. Trends Neurosci 30:350-356.

Huguenard JR, Prince DA (1994) Intrathalamic rhythmicity studied in vitro: nominal T-current modulation causes robust antioscillatory effects. J Neurosci 14:5485-5502.

Huntsman MM, Porcello DM, Homanics GE, DeLorey TM, Huguenard JR (1999) Reciprocal inhibitory connections and network synchrony in the mammalian thalamus. Science 283:541-543.

Jones EG (2007) The thalamus, Ed 2. New York: Cambridge UP.

Kano M, Ohno-Shosaku T, Hashimotodani Y, Uchigashima M, Watanabe M (2009) Endocannabinoid-mediated control of synaptic transmission. Physiol Rev 89:309-380.

Katona I, Urbán GM, Wallace M, Ledent C, Jung KM, Piomelli D, Mackie K, Freund TF (2006) Molecular composition of the endocannabinoid system at glutamatergic synapses. J Neurosci 26:5628-5637.

Kawamura Y, Fukaya M, Maejima T, Yoshida T, Miura E, Watanabe M, Ohno-Shosaku T, Kano M (2006) The CB1 cannabinoid receptor is the major cannabinoid receptor at excitatory presynaptic sites in the hippocampus and cerebellum. J Neurosci 26:2991-3001.

Kim U, Sanchez-Vives MV, McCormick DA (1997) Functional dynamics of GABAergic inhibition in the thalamus. Science 278:130-134.

Kreitzer AC, Carter AG, Regehr WG (2002) Inhibition of interneuron firing extends the spread of endocannabinoid signaling in the cerebellum. Neuron 34:787-796.

Lam YW, Nelson CS, Sherman SM (2006) Mapping of the functional interconnections between thalamic reticular neurons using photostimulation. J Neurophysiol 96:2593-2600.

Landisman CE, Connors BW (2005) Long-term modulation of electrical synapses in the mammalian thalamus. Science 310:1809-1813.

Landisman CE, Long MA, Beierlein M, Deans MR, Paul DL, Connors BW (2002) Electrical synapses in the thalamic reticular nucleus. J Neurosci 22:1002-1009.

Lee SH, Földy C, Soltesz I (2010) Distinct endocannabinoid control of GABA release at perisomatic and dendritic synapses in the hippocampus. J Neurosci 30:7993-8000.

Llinás R, Jahnsen H (1982) Electrophysiology of mammalian thalamic neurones in vitro. Nature 297:406-408.

Long JZ, Nomura DK, Cravatt BF (2009a) Characterization of monoacylglycerol lipase inhibition reveals differences in central and peripheral endocannabinoid metabolism. Chem Biol 16:744-753.

Long JZ, Nomura DK, Vann RE, Walentiny DM, Booker L, Jin X, Burston JJ, Sim-Selley LJ, Lichtman AH, Wiley JL, Cravatt BF (2009b) Dual blockade of FAAH and MAGL identifies behavioral processes regulated by endocannabinoid crosstalk in vivo. Proc Natl Acad Sci USA 106:20270-20275.

Long MA, Landisman CE, Connors BW (2004) Small clusters of electrically coupled neurons generate synchronous rhythms in the thalamic reticular nucleus. J Neurosci 24:341-349.

Maejima T, Oka S, Hashimotodani Y, Ohno-Shosaku T, Aiba A, Wu D, Waku K, Sugiura T, Kano M (2005) Synaptically driven endocannabinoid release requires $\mathrm{Ca}^{2+}$-assisted metabotropic glutamate receptor subtype 1 to phospholipase $\mathrm{C} \beta 4$ signaling cascade in the cerebellum. J Neurosci 25:6826-6835.

Mailleux P, Vanderhaeghen JJ (1992) Distribution of neuronal cannabinoid receptor in the adult rat brain: a comparative receptor binding radioautography and in situ hybridization histochemistry. Neuroscience 48:655-668. 
Marsicano G, Lutz B (1999) Expression of the cannabinoid receptor CB1 in distinct neuronal subpopulations in the adult mouse forebrain. Eur J Neurosci 11:4213-4225.

Marsicano G, Wotjak CT, Azad SC, Bisogno T, Rammes G, Cascio MG, Hermann H, Tang J, Hofmann C, Zieglgänsberger W, Di Marzo V, Lutz B (2002) The endogenous cannabinoid system controls extinction of aversive memories. Nature 418:530-534.

McCormick DA, Bal T (1997) Sleep and arousal: thalamocortical mechanisms. Annu Rev Neurosci 20:185-215.

Melis M, Perra S, Muntoni AL, Pillolla G, Lutz B, Marsicano G, Di Marzo V, Gessa GL, Pistis M (2004) Prefrontal cortex stimulation induces 2-arachidonoyl-glycerol-mediated suppression of excitation in dopamine neurons. J Neurosci 24:10707-10715.

Min R, Testa-Silva G, Heistek TS, Canto CB, Lodder JC, Bisogno T, Di Marzo V, Brussaard AB, Burnashev N, Mansvelder HD (2010) Diacylglycerol lipase is not involved in depolarization-induced suppression of inhibition at unitary inhibitory connections in mouse hippocampus. J Neurosci 30:2710-2715.

Monory K, Blaudzun H, Massa F, Kaiser N, Lemberger T, Schütz G, Wotjak CT, Lutz B, Marsicano G (2007) Genetic dissection of behavioural and autonomic effects of Delta(9)-tetrahydrocannabinol in mice. PLoS Biol 5:e269.

Ohno-Shosaku T, Tsubokawa H, Mizushima I, Yoneda N, Zimmer A, Kano M (2002) Presynaptic cannabinoid sensitivity is a major determinant of depolarization-induced retrograde suppression at hippocampal synapses. J Neurosci 22:3864-3872.

Pan B, Wang W, Long JZ, Sun D, Hillard CJ, Cravatt BF, Liu QS (2009) Blockade of 2-arachidonoylglycerol hydrolysis by selective monoacylglycerol lipase inhibitor 4-nitrophenyl 4-(dibenzo[d][1,3]dioxol-5-yl(hydroxy)methyl)piperidine-1-carboxylate (JZL184) enhances retrograde endocannabinoid signaling. J Pharmacol Exp Ther 331:591-597.

Paré D, Hazrati LN, Parent A, Steriade M (1990) Substantia nigra pars reticulata projects to the reticular thalamic nucleus of the cat: a morphological and electrophysiological study. Brain Res 535:139-146.

Potter GB, Petryniak MA, Shevchenko E, McKinsey GL, Ekker M, Rubenstein JL (2009) Generation of Cre-transgenic mice using Dlx1/Dlx2 enhancers and their characterization in GABAergic interneurons. Mol Cell Neurosci 40:167-186.
Regehr WG, Carey MR, Best AR (2009) Activity-dependent regulation of synapses by retrograde messengers. Neuron 63:154-170.

Sanchez-Vives MV, McCormick DA (1997) Functional properties of perigeniculate inhibition of dorsal lateral geniculate nucleus thalamocortical neurons in vitro. J Neurosci 17:8880-8893.

Sohal VS, Huguenard JR (2003) Inhibitory interconnections control burst pattern and emergent network synchrony in reticular thalamus. J Neurosci 23:8978-8988.

Tanimura A, Yamazaki M, Hashimotodani Y, Uchigashima M, Kawata S, Abe M, Kita Y, Hashimoto K, Shimizu T, Watanabe M, Sakimura K, Kano M (2010) The endocannabinoid 2-arachidonoylglycerol produced by diacylglycerol lipase alpha mediates retrograde suppression of synaptic transmission. Neuron 65:320-327.

Tzounopoulos T, Rubio ME, Keen JE, Trussell LO (2007) Coactivation of pre- and postsynaptic signaling mechanisms determines cell-specific spike-timing-dependent plasticity. Neuron 54:291-301.

van Rijn CM, Gaetani S, Santolini I, Badura A, Gabova A, Fu J, Watanabe M, Cuomo V, van Luijtelaar G, Nicoletti F, Ngomba RT (2010) WAG/Rij rats show a reduced expression of $\mathrm{CB}$ receptors in thalamic nuclei and respond to the CB receptor agonist, $\mathrm{R}(+)$ WIN55,212-2, with a reduced incidence of spike-wave discharges. Epilepsia 51:1511-1521.

Venance L, Piomelli D, Glowinski J, Giaume C (1995) Inhibition by anandamide of gap junctions and intercellular calcium signalling in striatal astrocytes. Nature 376:590-594.

von Krosigk M, Bal T, McCormick DA (1993) Cellular mechanisms of a synchronized oscillation in the thalamus. Science 261:361-364.

Wu CS, Zhu J, Wager-Miller J, Wang S, O'Leary D, Monory K, Lutz B, Mackie $\mathrm{K}, \mathrm{Lu} \mathrm{HC}$ (2010) Requirement of cannabinoid CB(1) receptors in cortical pyramidal neurons for appropriate development of corticothalamic and thalamocortical projections. Eur J Neurosci 32:693-706.

Yoshida T, Fukaya M, Uchigashima M, Miura E, Kamiya H, Kano M, Watanabe M (2006) Localization of diacylglycerol lipase-alpha around postsynaptic spine suggests close proximity between production site of an endocannabinoid, 2-arachidonoyl-glycerol, and presynaptic cannabinoid CB1 receptor. J Neurosci 26:4740-4751.

Zhang L, Jones EG (2004) Corticothalamic inhibition in the thalamic reticular nucleus. J Neurophysiol 91:759-766. 